\title{
Community Preparedness for Disasters in Delhi: An Empirical Evaluation
}

\author{
By Upma Gautam ${ }^{1}$, Deeksha Bajpai Tewari ${ }^{2}$
}

\begin{abstract}
Background: During a disaster, the community remains the primary and the sole line of response for quite long time period and therefore, incorporating local communities in disaster recovery and risk reduction is crucial, critical component. Aim: Evaluating the vulnerability of a selected society on four aspects: Information, Awareness, Training and Preparedness in a multi hazard prone state of Delhi, India, constitutes the central focal point of this study. Methodology: The data primarily was collected through two separate questionnaires administered to the sample of 726 respondents in the age group of 15 - 75 years. Community was sub-divided into two groups - First included professionals, housewives, retired persons $(n=280)$ and second included students of school $(n=160)$ and college/university level $(\mathrm{n}=286)$. The sampling technique employed was stratified random with methodology as empirical and analytical. Findings: The study affirms, firstly, that there is lack of awareness of the community about disaster plan, its components and agencies entrusted with disaster planning; secondly, there is a vague understanding about their role both during and post disaster; thirdly, significance of participation in training is also underestimated. Recommendations: A roadmap for increasing resilience of communities through effective training and outreach programs for capacity building up for the 'whole' community.
\end{abstract}

Keywords: Disaster risk reduction, community preparedness, resilience, participation, disaster management

\section{Introduction and Background}

Disasters, in general, are spontaneous, random, and catastrophic thereby disrupting the normalcy in the societal functioning. The United Nations defines disaster as hazards which not only aggravates the vulnerable conditions of any community wherein huge losses to human lives, property and environment is involved but also is in excess to the community's ability to deal with it through the available resources which differentiates it from an emergency wherein no external response is required and the situation can be handled locally (Pal, I., \& Ghosh, T., 2018). Disasters, based on the origin, can be broadly categorized into natural and man-made with a commonality of serious loss of both, life and property. Somehow the contemporary understanding about disasters negates this differentiation wherein disasters are either defined as the natural events where either there is lack of community preparedness or in alternate resulting from the combination of a hazard and vulnerability. Any hazard, may it be earthquake, flood, cyclone, tsunami, is a trigger resulting into a disaster when gets coupled up with the vulnerabilities like inadequate preparedness, disabled or senior population leading massive disruption in societal functioning and also loss of property and life.

$\mid{ }^{1}$ Assistant Professor, University School of Law and Legal Studies, Guru Gobind Singh Indraprastha University, Delhi, India

${ }^{2}$ Assistant Professor, Department of Geography, Dyal Singh College, University of Delhi, India. *Corresponding Author 
During a disaster, community remains in the front line of response for quite long time period, sometimes extending from 72 hrs to weeks (Brennan et al., 2005), and therefore the role of participation of a community in an effective disaster risk reduction strategy is been stressed out in varied research studies (Crawford et al., 2013; Slotterback et al., 2012). It is contended that the community empowerment through preparedness at the local level before the disasters is the key to ensure success of disaster recovery projects (Davidson et al., 2006), and if the societal capacity is enhanced and the community is well prepared, it not only decreases the casualties but also makes the rehabilitation process easier making the societies resilient (Rowlands, 2013). Further, there are success stories of rebuilding the wrecked societies due to disasters through united efforts of varied stakeholders locally but also by the regional cooperation amongst nations (Anderson, 2008; Bornstein et al., 2013; Bolin, 2006).

It's been long that the community is seen as victims and an outside helping hand is seen as mandatory measure for the return of the community "back to normal" (Berke et al.,1993; Hewitt, 1998). Rather, in last few decades, the limelight has been reallocated towards the role of community preparedness in reducing the risk of disaster and recovery thereafter and for the aforesaid purpose the significance of local awareness, participatory attitude and control in determining the nature of disaster response is well acknowledged. The countries of the entire South Asian subcontinent are prone to disaster and Indian subcontinent owing to its unique geophysical location, geo climate conditions and unpredictable monsoons is extremely prone to such natural disasters. Specifically, the National Capital Region of Delhi is a multi-hazard state. Located in the seismic zone IV makes it prone to earthquakes. It is also prone to floods, urban fires as well as extreme heat \& cold waves. As the political capital and an established economic hub, it is also a likely target for terrorism related disasters. Out of 11 revenue districts of NCT of Delhi, East Delhi District is the most disaster-prone district.

As discussed above, in the times of a disaster, the members of a community stand to lose the most as they are in direct line of attack from either major or minor disasters. However, the impact of such disasters on the community can be mitigated. The concept of 'Community-Based Disaster Management' (CBDM) gains prominence leading such a scenario wherein the communities are the pallbearers of responsibility. The CBDM approach enhances the capacity building of the people thereby enabling the responses during crisis which is materialized by increasing access and control over resources and basic social services. It focuses on evaluation of situations so that plans and decisions can be made with community involvement resulting not only in strengthening of communities but also facilitating them to take on programs for better preparedness against disasters.

Since continued action at community level is prerequisite in its preparation and responding against natural disaster, the present study intends to undertake this task of evaluating the level of information available to different stakeholders of the communities; assess their preparedness in an eventuality of a disaster and to suggest measures to strengthen the Community Based Disaster Management practices. 


\section{Study Area: Patterns of Disasters}

Delhi is continuously at risk to varied hazards both natural and man-made. Mapping of vulnerabilities and hazards amongst 640 districts undertaken by National Disaster Risk Assessment Index in association with Union Home Ministry and UNDP, which is still in draft form, has placed NCT Delhi as the most vulnerable UT of the nation.

Delhi: Hazard Assessment

\begin{tabular}{|c|c|c|c|c|c|c|c|c|c|c|c|}
\hline Districts & $\begin{array}{l}\text { Dै } \\
\text { Z }\end{array}$ & 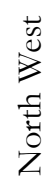 & 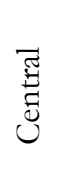 & $\stackrel{\vec{\infty}}{\vec{y}}$ & $\begin{array}{l}\overrightarrow{0} \\
\overrightarrow{0} \\
\vec{B} \\
\vec{E} \\
0 \\
0\end{array}$ & $\begin{array}{l}\vec{\Xi} \\
\overline{\bar{\Xi}} \\
0 \\
\vec{B} \\
Z\end{array}$ & $\begin{array}{l}\tilde{I} \\
\stackrel{Z}{\Xi} \\
0\end{array}$ & 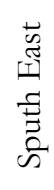 & 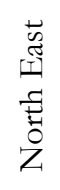 & 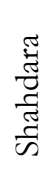 & 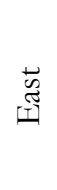 \\
\hline \begin{tabular}{|l|} 
Earthquake \\
\end{tabular} & III & III & III & III & III & III & III & III & III & III & III \\
\hline Flood & II & - & III & II & II & $\mathrm{I}$ & $\mathrm{I}$ & III & III & $\mathrm{I}$ & III \\
\hline Fire & II & III & III & III & III & III & III & III & III & III & III \\
\hline Building Collapse & III & III & III & III & III & II & II & III & III & III & III \\
\hline Epidemics & II & II & II & II & II & III & II & II & II & II & II \\
\hline Urban Floods & II & II & III & II & III & II & II & II & III & III & III \\
\hline Industrial Hazard & $\mathrm{I}$ & III & II & II & II & III & III & $\mathrm{I}$ & III & III & III \\
\hline Terrorist Attack & $\mathrm{I}$ & II & II & III & II & III & III & III & II & II & II \\
\hline
\end{tabular}

\begin{tabular}{|c|c|c|c|}
\hline \multicolumn{4}{|c|}{ Vulnerability } \\
\hline III & II & I & - \\
\hline High & Moderate & Low & Nil \\
\hline
\end{tabular}

Out of the eleven districts of Delhi, all are highly prone to earthquakes. Ten out of eleven districts are prone to fire and nine out of the total eleven districts are prone to building collapse. North east and east districts are most disasters prone districts of Delhi. Further, during floods and earthquakes the soil around Yamuna river which is soft and alluvial exposes the region to massive damages. Moreover, the loss to life and property increases manifold when the factors like poor preparedness and awareness amongst community members who themselves are at risk due to high population density in scattered slums or in clusters in poor housing conditions get coupled up with 'not so' prepared administrative response in the times of disaster.

\section{Methodology}

As a preliminary step, the stakeholder groups in a community are identified. Following groups are selected: Schools/school children, University Students, Working Professionals, Housewives and retired Persons, members of the Resident Welfare Associations. This is an empirical field- oriented research. A questionnaire is developed by the researchers based on the objectives of the study. Based on the scope and objective of research, this study primarily focuses on the qualitative approach and to support the arguments and to have a detailed sense of the community secondary statistical data is 
used. Published reports of various agencies like District Disaster Management Agency, Directorate of Education etc. are thoroughly studied.

The sampling technique employed in the study is stratified random in nature. Stratified sampling requires selection of respondents in such a way that they represent the various strata of the universe and selection within the strata will be random in nature. In this specific study, the target group are the members of various strata selected from the universe.

For this study, two separate questionnaires were developed. One to record the responses of the community members including- professionals, housewives, retired persons, members of the Resident Welfare Associations. The other one was prepared to record the responses of the students- both school students and the college and university students. Both the questionnaires were prepared to gauge the awareness and the preparedness of the community stakeholders in case of a disaster. Total 726 responses could be recorded. Out of which 280 members of the community, 160 school students, and 286 university students responded.

\section{Respondent Demographics: Community Stakeholders}

The questionnaire was distributed to people living in different localities of Delhi. 280 questionnaires were completed and returned. Out of 280 respondents, 120 were males $(42.85 \%)$ and 160 were females $(57.14 \%)$. The implication of sex and gender in disasters is difficult to capture especially when used simply to note the relative numbers of women and men. Role of women in preparing themselves and as active members of the community becomes vital at every stage of disaster risk reduction. It has been a welldocumented fact that safety concerns of their families have been a strong motive underlying women's involvement in environmental protection movements.

The respondents' age ranged between 15-75 years. Half of the respondents worked in the government sector, another 31 percent worked in different private enterprises, 10 percent were self-employed, 07 percent responded their profession as "others" which included freelance, theatre work, NGOs etc.

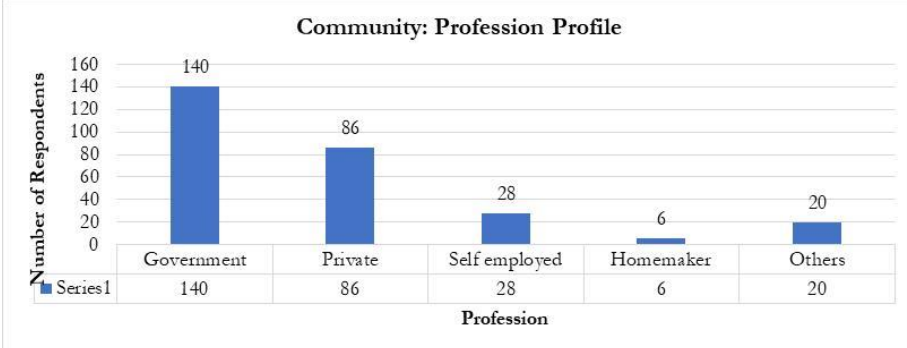

The educational levels of the respondents ranged from matriculation to Post-Graduation. Delhi being a cosmopolitan city and an amalgamating hub of manufacturing, services, trade and transport etc, the community showed a great diversity in educational achievements. Even though there is tacit understanding about the affiliation between education and vulnerability to disaster, but an analogy can be drawn from the documentation of the fact 
that education, awareness and preparation for disaster are interrelated. It is contended that the capacity of individual members and community as a whole to prepare, respond and recover from disaster primarily depends and is directly proportional to its capability of effectively assessing a situation and thereafter taking informed decisions for the purpose of mitigating losses and such capability is greatly influenced by the education levels of the populace(Santos- Hernandez and Morrow (2013)).

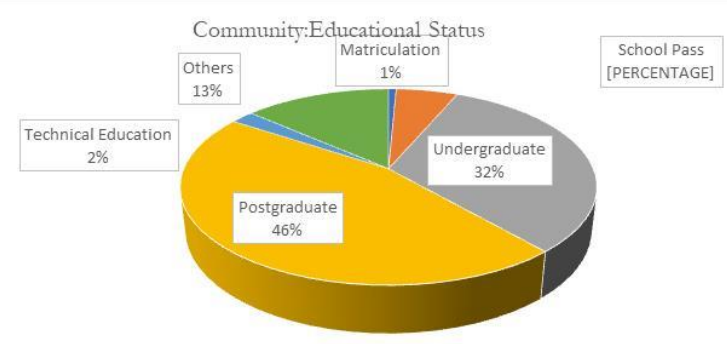

As stated earlier, the community studied since was part of a metropolitan city, was largely educated. Only 13 percent of the total respondents stated their educational status as others including uneducated. Although, when inquired further, most of these uneducated were found to be literate.

\subsection{Structural Characteristics}

Since all the districts of Delhi are multi disasters risk prone, structures, buildings and their construction is of utmost relevance. Since Delhi lies in Zone IV, there can be earthquakes of 7 to 7.9 magnitudes. Most of the houses in Delhi are not earthquake resistant. Also, there are many illegal colonies flouting safety norms. If an earthquake of 7 or more than 7 magnitude hits Delhi, then the national capital can suffer huge losses. The built structures in the city consist mainly of concrete or brick which is not adequately reinforced making them highly vulnerable buildings. The clogged and overpopulated neighbourhoods in Old Delhi and East Delhi are extremely vulnerable multi-story brick buildings with irregular configurations. To compound the issue, there seems to be no regulatory or quality control exercised upon completion. Even though Delhi is working towards resolving these glaring loopholes pertaining to illegal buildings, but the progress is slow.

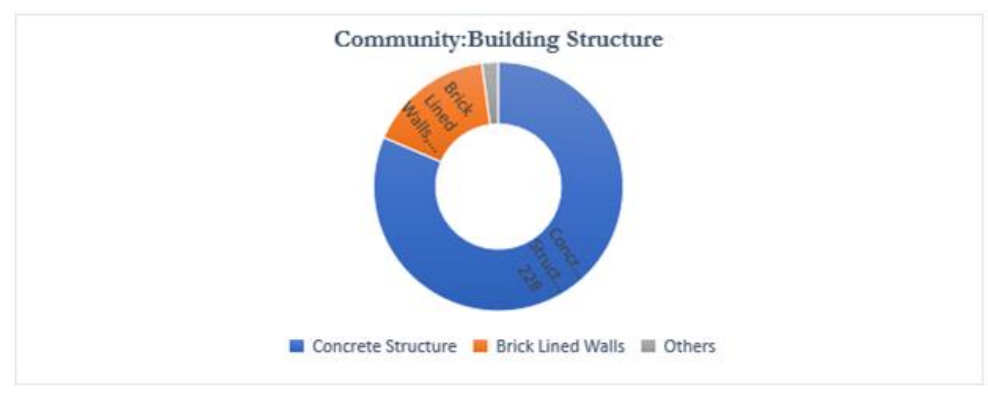


In the study area of the National Capital Territory of Delhi, an overwhelming majority of 258 respondents (92.14 percent) were residing in authorized colonies, however 22 respondents (7.85 percent) also reported that they were still residing in unauthorized colonies. 82 respondents were residing in congested areas and 198 respondents (70.71 percent) were living in open and planned areas. While assessing the type of residential building structure, 81.42 percent of the respondents, both males and females, reported that they were living in concrete structures, about 8.21 percent reported to be residing in buildings with brick lined walls. These were the respondents living in the unauthorized colonies.

An aspect of buildings and structures that prove crucial in areas prone to earthquakes is the density of buildings and structures. In the study area, 126 (45 percent) respondents resided in the multi-storied buildings, another 124(44.28 percent) lived in three storied buildings. This reflects the extremely high density of population in the community. This is an important indicator of the vulnerability of the community prone to multiple disasters like earthquakes, fires etc. As stated earlier, Delhi being a multi hazard prone area and specifically being both earthquake and fire prone should have structures which are resistant to fire and earthquakes but being the most densely populated UT of India with 11,297 persons per square kilometre, the contrary seems to be true.

\subsection{Community: Understanding Disasters}

In order to gauge the respondents' understanding of the disaster, 260 (93 percent) responded in affirmative and only about 07 percent responded in negative. But while asked to write a definition of a disaster most of the community members were reluctant to elaborate. Their responses ranged from vague description like an unfortunate event, unforeseen event and disaster is a national problem to specific descriptions like events involving loss of life and property etc.

\subsection{Community: Forums for Disaster Training}

Sources and forums of learning about the disaster management is also an important parameter to understand its importance. A high proportion of the respondents 104 (37 percent) received the knowledge about disaster management at school level. It thus became clear that the school-oriented preparedness plan and disaster risk reduction trainings hold a crucial significance in building disaster resilient communities. 82 (29.28 percent) responded that they have not received any training regarding disaster preparedness. Besides formal education at school level, knowledge about disaster management can also be gained at graduate and post graduate levels. Even it can be understood by attending special lectures and demonstrations. Through such modes of informal education, capacity of the community on disaster management can be developed. But, these forums' role in building disaster prepared communities seemed minimal in the communities studied. Besides school level disaster preparedness training, only demonstrations by the disaster management agencies were the only other source of disaster management training that was accorded to the communities. 14.28 percent of the respondents gained the disaster preparedness training through demonstrations by the disaster management agencies. 


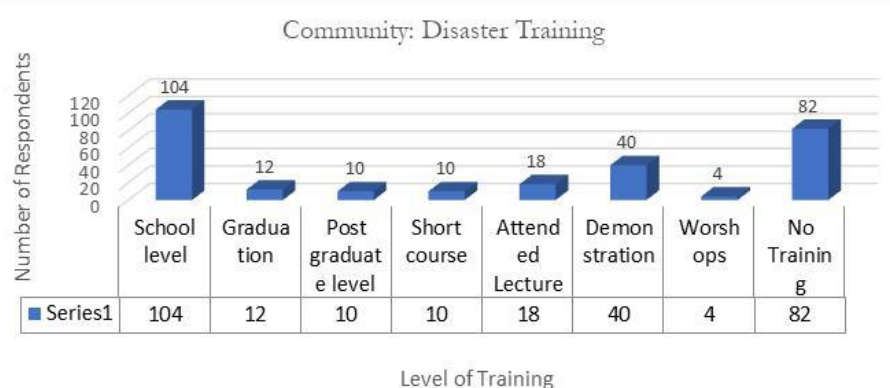

About 35 percent of the respondents claimed that their first knowledge about disaster management was before the age of 15 years and 59 percent replied that the information about disasters were received in school. Another 34 percent of the members of the community emphasised the role of media in disseminating information about disasters and spreading information about the significance of preparedness of a community during a disaster. Other sources of information like friends, relatives, experts and internet seemed to play a reduced role of sources of information in case of disaster preparedness.

\subsection{Community: Personal Knowledge/ Experience of a Disaster}

In order to ascertain the level of personal experiences of respondents, of encountering any natural or manmade disaster, 100 (about 36 percent) had encountered man-made disasters, 124(44 percent) had experienced natural disasters. The other respondents did not reply to the question. Those who had replied for the man-made disasters had experienced, fire, riots, accidents and gas leakage. As regards to those who had experienced natural disasters, mostly had seen only earthquakes, followed by floods and lighting.

Knowledge of disasters which can occur in Delhi is an important input for working out training modules and will charter the course of disaster preparedness plan of Delhi. Answering the question, 242 (86.42 percent) said that Delhi is prone to earthquakes, 52.85 percent respondents reported accidents and building collapse were the other disasters which could happen in the residential area.

Similarly, knowledge of seismic zone in which the residential area was located was an important input, only 10 respondents gave the correct answer. A large proportion of the residents had no information about earthquake zonation and thus provided no answer to the question.

\subsection{Community: Disaster Plan/ Preparedness}

Only 16 respondents (5.71 percent) had a family disaster plan. On the contrary, 222 (79.28 percent) had the knowledge about the relevance of having a family disaster plan. 86 (about 31 percent) of the respondents had no idea about the disaster management plan and its constituents. 192 (about 69 percent) of the respondents had the knowledge that all the structures must be constructed as per the National Building Code (NBC). In response to the question, whether their building is as per the norms, about 64 percent showed no inclination and no information about the same. Only 76 respondents (27.14 percent) responded in affirmative to take some steps to bring the building to the 
NBC. Rest 73 percent replied in negative.

Knowledge of emergency contact numbers is a must for any awakened community, so that they could intimate soon after a disaster takes place, without losing any precious time. People should be fully aware about whom to inform in case of man-made disasters. Although various stakeholders are there to respond to such disasters, however the information should be provided to right kind of stakeholders in the shortest possible time. Various stakeholders in disaster response are - Police, Fire \& Emergency Services, District Disaster Management Control Room, Ambulance Services etc. 146 (52.14 percent) of the respondents, were of the view that they would inform all the above stated agencies in case of a disaster.

204(72.85 percent) of the respondents had Residents Welfare Associations (RWA) in their locality. 164 (58.57 percent) of the respondents either responded that their RWAs have no disaster management plans or they have no idea or information about the existence of such a plan. 162 (about 63 percent) respondents had either none or no information about dedicated disaster management teams in their area. 216 (77.14 percent) respondents replied that there are no mock drills about disaster preparedness in their area. 224 ( 80 percent) of the respondents have never participated in any mock drills of disaster preparedness in their area.

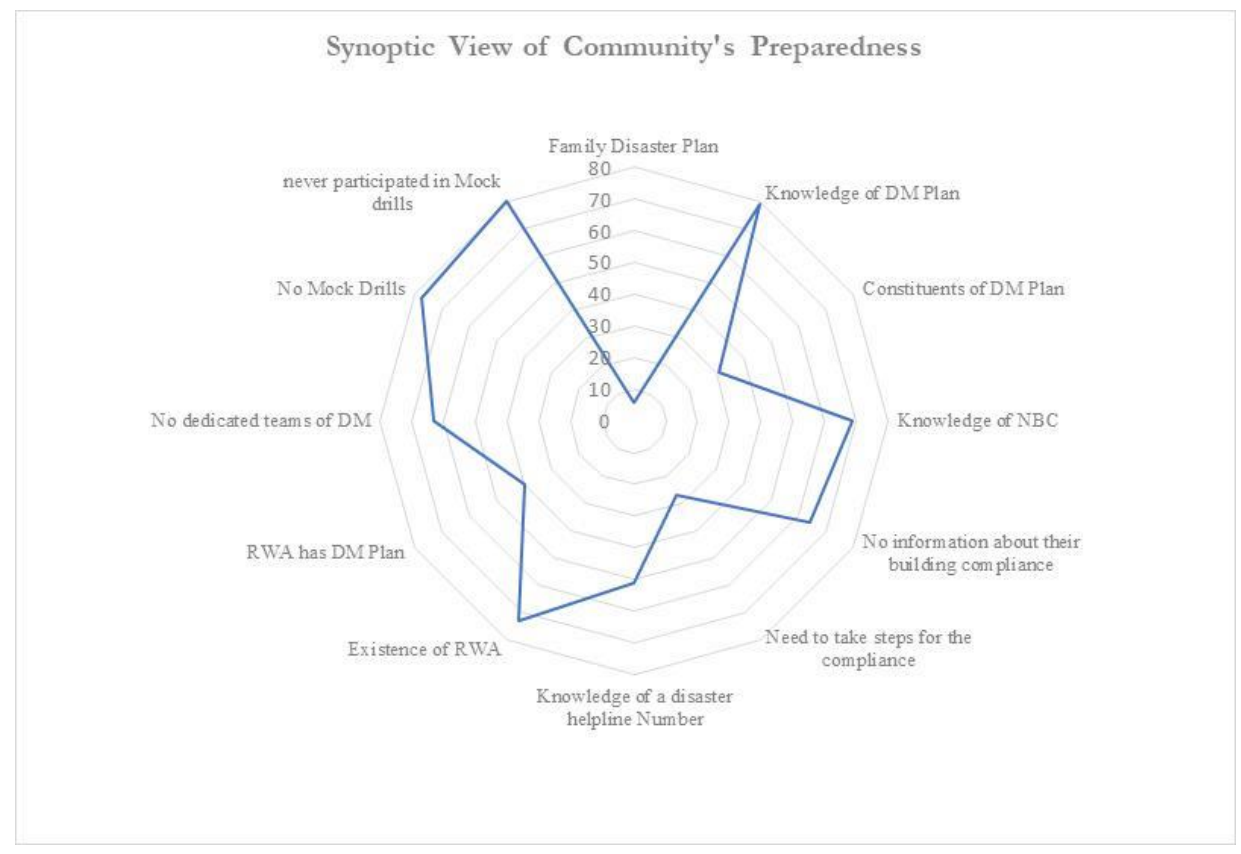

\section{Students: Disaster Awareness and Preparedness}

There are several ways for preparing the students, teaching and non-teaching staff for the times of disaster or any such emergency, amongst which building up the infrastructure strictly according to the code and frequent drills are most significant 
measures. Building a prior awareness about the vulnerability of their area, propensity and type of expected disaster equips the students and staffs to not only respond quickly but also makes recovery faster and effective which also forms the part of the objectives laid down by Hyogo Framework for Action, 2005-2015, pertaining disaster education.

Disaster risk reduction strategy ideally is based on three approaches, firstly, individual preparedness for the unseen but expected emergent situation; secondly, participatory role of educational institutions in such preparedness; and thirdly, collaborative spread of awareness about such preparedness measures through these students in their families and community thereon (Mulyasari et al., 2011). It's for this reason that school and university students form the focal point for the implementation of this strategy by not only building awareness amongst them but also inculcating a culture of resilience within.

\subsection{Respondents Demographics: Students}

In the study area, a total of 446 students' awareness and preparedness of disasters were studied. In this study, a well-designed questionnaire was prepared and distributed among 446 students selected randomly from different schools and Colleges of Delhi. The consent of the students was taken prior by explaining them the purpose and methodology of the undertaken study. A self-administered questionnaire based on detailed literature review, for assessing the knowledge and awareness of the students was employed as a research tool. Out of these, 160 were school students and 286 were college/ university students. In school students, 69(43.12 percent) were male and 91(56.87 percent) were females. In University students, 174 (60.83 percent) were male and 112 (39.16 percent) were females. About 71 percent of the school students belonged to age group of under 18 years of age. About 78 percent of the University students belonged to 18-24 years of age.

\subsection{Students: Awareness of Disasters}

The students in the study area were aware of the importance of propagating and disseminating information about disasters and disaster preparedness to the community as revealed by their keenness to inform their peer about the same. 62.5 percent of the school students and 72.02 percent of the University students responded to let their peer have information about disaster propensity and likelihood of their occurrence.

Awareness of the school students about the variety of disasters that can affect their area is mixed. On one hand, about 75 percent of them are aware that Delhi is earthquake prone but only 36 percent of the school respondents were aware that flood also is a high frequency disaster that can afflict Delhi. 20 percent of the respondents also wrongly believed that Tsunami could hit Delhi. About 34 percent of the respondents also wrongly believed that hurricane and tornado can hit Delhi. Amongst the university students, about 42 percent students were aware that Delhi can be hit by an earthquake, but 65 percent students stated that the study area is not flood prone. But, in comparison to the school students, the responses of the college/University students were more aware and did not mistakenly identified that the city can be hit by disasters like Tsunami, tornado etc.

More than 62.5 percent students, school as well as college/university students responded that they have knowledge about different types of disasters that can occur in their area. 
About 73 percent responded that they have enough information about steps required for the management of disasters that can afflict their areas.

\subsection{Students: Level of Preparation of Disasters}

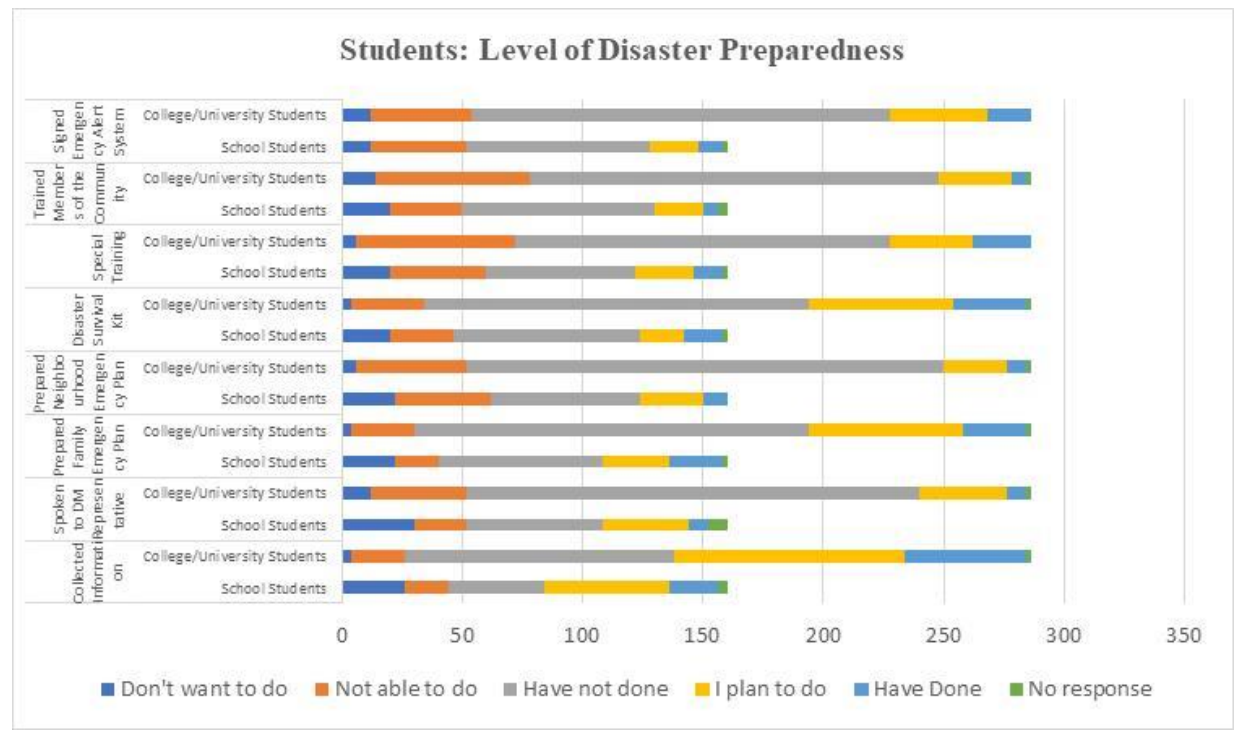

On a wide-ranging question to assess the level of awareness and preparedness of students about disasters and its management in their area, the students were asked questions pertaining to their level of information and action taken for disaster preparedness. As is evident from the figure above, all the answers in negative, whether 'not able to do', 'have not done' together outnumbers all other responses. More the active participation enquired; a greater number of negative answers were provided. In addition, among the school students, the response 'don't want to do' was also a disturbing trend witnessed. This lackadaisical approach to disaster preparedness does not ogre well for the future. As stated earlier, role of students at an individual level to be aware of and prepare for disasters is crucial in them acting as the first level of community soldiers in the critical fight for disaster mitigation.

Students' role in preparing their families and thereby the community also cannot be undervalued. If trained well, students can form the first level of information disseminators for the community pre, during and post disaster. Questions pertaining to the existence of an emergency plan, policies for disaster management at the government level, at the community level were asked to the students. The students were aware of the policies prepared by the country for tackling disasters but such policies at the local level were not known to the students. More than 50 percent of the students reported that besides themselves, there are other family members too who can carry out the emergency plan in their family.

A detailed check list of the availability of the contents of the emergency planning for disasters by the students were also undertaken. A large proportion of the students were 
ready with different components of the disaster management kits. But, some essential items like flashlight, supplies for children aged and other special needs persons were not available to the students and the information regarding their supplies were also absent. Emergency operation plans, evacuation plans were also absent.

Evaluating the vulnerability of a community on four aspects: Information, Awareness, Training and Preparedness, it was evident that students individually as well as part of the community had information, were aware of the disasters but whereas training and preparedness were concerned lacked the essential requisites.

\section{Students: Preparations for the Components of the DM Kits}

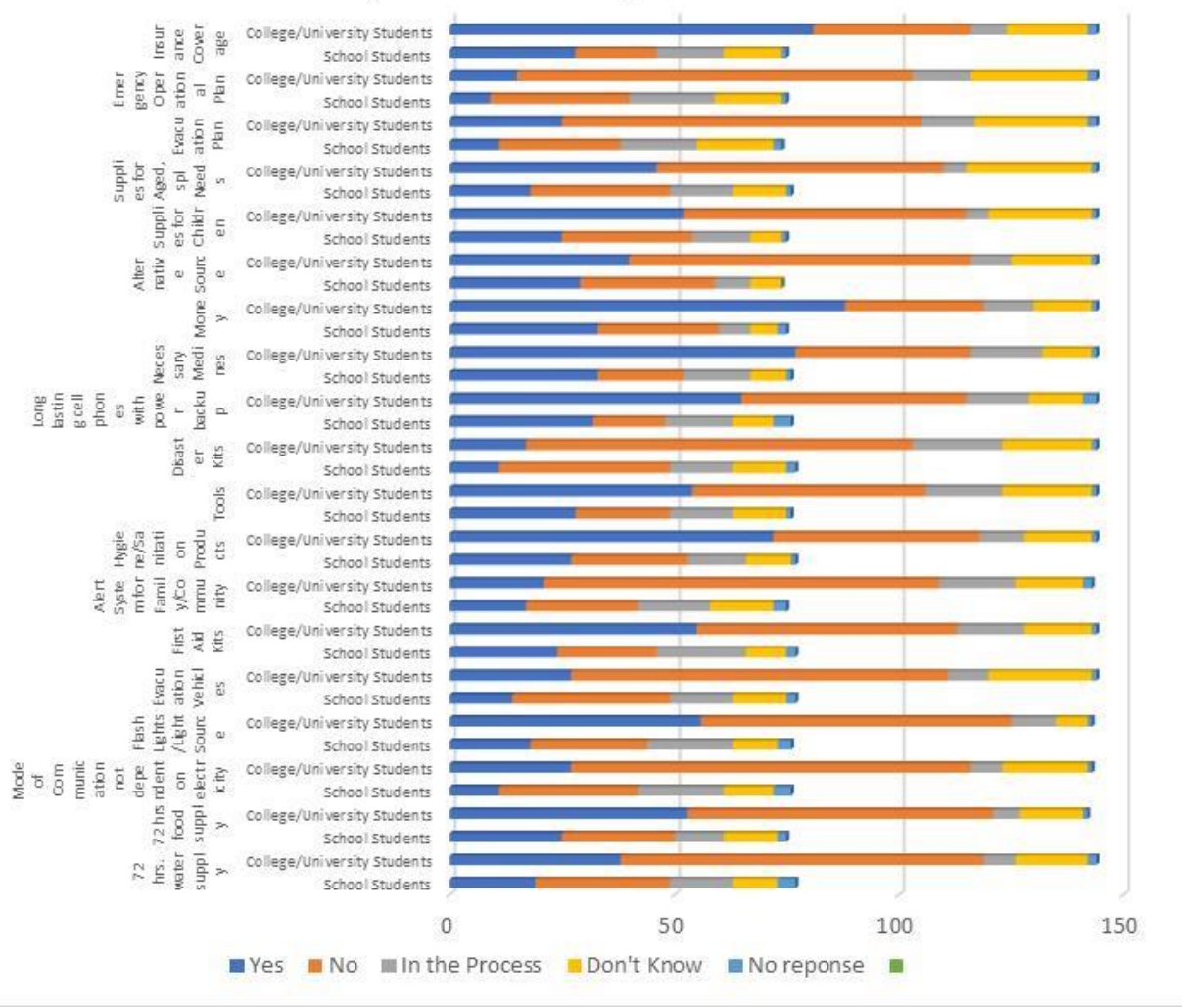

\section{Conclusion and Suggestion}

Disasters promote opportunities and when approached through communitybased collaborations can result into better preparedness thereby significantly mitigating the disaster risks and associated loss. Resilience is also been examined by the researchers as a form of adaptation where people adjust to a "new normal" and refuses to return to the conditions that caused the impact (Liu et al., 2011). Resilience is argued to be transformative wherein it is realized after reaching a point that the previous communities and their functioning is no longer sustainable and therefore the existing resources are organized and utilized in a way which reduces the future threats potentially. 
Identifying the stakeholders, falling into different categories, and their varied needs including their vulnerability and fragility, is the first step toward the capacity building of the community. Though census data can give an idea of the general overview of the population but generally such data may lack emerging populations including migrants, homeless, displaced and like which may increase the loss to life. Such needs instead of census data are better identified by the local community groups. Further, frequent interaction between varied social organizations, NGOs, faith based organizations to such vulnerable population and mutual collaborative efforts will result into building up of useful network which in turn will not only make the community aware of the existing possibilities of disasters but also will aid in helping themselves in case of any such event. The concept of community as a 'whole' can be a guiding principle for building up the effective practices resulting into better community preparedness. The said concept encourages the involvement of the community with an acknowledgment that the government centric approach is not sufficient in disaster risk reduction and therefore complete engagement of the diverse interest groups is necessary for capacity building within a community i.e. taking community as a 'whole'(Marsh \& Buckle, 2001).

Disaster recovery starts before the disaster even occurring and this recovery is termed as preparedness, where the community gets ready for the future events. This pre-disaster preparedness has a vivid impact upon a community's ability to respond to and recover from a disaster. It is contended that communities that are serious about disaster recovery - 'preparedness', firstly tend to focus on activities improvising responses during emergencies such as making themselves aware about systems and technologies pertaining to warning, evacuation, power restoration and debris management. The suggested roadmap for capacity building up for the 'whole' community firstly includes the dedicated research pertaining the past disaster events so as to identify the patterns in the population majorly impacted in terms of deaths and injuries so as map out the vulnerabilities and further strengthening them . Further, convening public meetings in public forums wherein not only the disaster preparedness strategies are discussed, improvised by the given suggestions by the active involvement of the local community based, faith based and the civic organizations in the effort, but also making the community becoming aware about the authorities to be trusted during the times of need. Training of agencies, organizations, workers and volunteers along with developing and maintaining communication channels amongst the social networks will also minimize and prevent disaster impacts. Lastly, integrating disaster reduction strategies into local and regional development plans will make all the difference but then this also will realize the desired goal when the community is intelligibly differentiated, and the needs are taken care accordingly in such plans.

Acknowledgement: The study was funded under Faculty Research Grant Scheme (FRGS), Guru Gobind Singh Indraprastha University, Dwarka, New Delhi. 


\section{References}

Anderson, W. (2008). Mobilization of the black community following Hurricane Katrina: From disaster assistance to advocacy of social change and equity. International Journal of Mass Emergencies and Disasters, 26(3), 197-217. Retrieved from http://ijmed.org/articles/293/.

Berke, P. J., Kartez, \& Wenger, D. (1993). Recovery after Disaster: Achieving sustainable development, mitigation and equity. Disasters, 17(2), 93-109. doi: 10.1111/j.1467-7717.1993.tb01137.x.

Bolin, R. (2006). Race, Class, Ethnicity, and Disaster Vulnerability. In H. Rodriguez, E. Quarantelli, \& R. R. Dynes (Eds.), Handbook of Disaster Research (p. 113-129). New York: Springer.

Bornstein, L., Lizarralde, G., Gould, K., \& Davidson, C. (2013). Framing responses to post-earthquake Haiti: How representations of disasters, reconstruction and human settlements shape resilience. International Journal of Disaster Resilience in the Built Environment, 4(1), 43-57. doi: 10.1108/17595901311298991.

Brennan, M. A., Flint, C., \& Barnett, R. (2005). Community Volunteers: The Front line of disaster response, The Journal of Volunteer Administration, 23(4), 52-56. Retrieved from https://www.researchgate.net/publication/310594259_Community_volunteers_the_front_line_o f_disaster_response.

Bryson, J., Quick, K., Slotterback, C., \& Crosby, B. (2012). Designing Public Participation Processes. Public Administration Review, 73(1), 23-54. doi: https://doi.org/10.1111/j.1540-6210.2012.02678.x.

Crawford, L., Langston, C., \& Bajracharya, B. (2013). Participatory project management for improved disaster resilience. International Journal of Disaster Resilience in the Built Environment, 4(3), 317-333. doi: 10.1108/IJDRBE-07-2012-0020.

Davidson, C. H., Johnson, C., Lizarralde, G., Dikmen, N., \& Sliwinski, A. (2006), Truths and myths about community participation in post-disaster housing projects. Habitat International, 31(1), 100-115. doi: 10.1016/j.habitatint.2006.08.003.

Hewitt, K. (1998). Excluded perspectives in the social construction of disaster. In E. L. Quarantelli (Ed.), What is a disaster? Perspectives on the Question (p. 75-91). New York: Routledge.

Liu, A., Anglin, R., \& Plyer, A. (Eds.). (2011). Resilience and opportunity: Lessons from the U.S. Gulf Coast Katrina and Rita. Washington, DC: Brookings Institution.

Marsh, G., \& Buckle, P. (2001). Community: The Concept of community in the risk and emergency management context. Australian Journal of Emergency Management, 16(4), 5-7. Retrieved from https://www.researchgate.net/publication/291998553_Community_The_concept_of_community _in_the_risk_and_emergency_management_context.

Mulyasari, F., takeuchi, Y., \& Shaw, R. (2011). Chapter 7 Implementation Tools for Disaster Education. In R., Shaw, K., Shiwaku, \& Y., Takeuchi. (Eds.), Disaster Education (Community, Environment and Disaster Risk Management (p. 137-151). Bingley: Emerald Group Publishing Limited.

Pal, I., \& Ghosh, T. (2018). Natural Hazards Management in Asia. New Delhi: Sage Publications India Pvt. Ltd.

Pearce, L. (2003). Disaster Management and Community Planning, and Public Participation: How to Achieve Sustainable Hazard Mitigation. Nature Hazards, 28, 211-28. doi: https://doi.org/10.1023/A:1022917721797.

Rowlands, A. (2013). Disaster Recovery Management in Australia and the Contribution of Social Work. Journal of Social Work in Disability \& Rehabilitation, 12(1-2), 19-38. doi: 10.1080/1536710X.2013.784173.

Thakur, P., \& Chauhan, N. (2018). Delhi most vulnerable UT in India's first disaster risk index, Maharashtra leads states. The Times of India. Retrieved from https://timesofindia.indiatimes.com/india/delhimost-vulnerable-ut-in-indias-first-disaster-risk-index-maharashtra-leadsstates/articleshow/64525085.cms.

Yamori, K. (2012). Using Games in Community Disaster Prevention Exercises. Group Decision and Negotiation, 21(4), 571-83. doi: https://doi.org/10.1007/s10726-011-9227-9. 